\title{
ANÁLISE SISTÊMICA PRELIMINAR DAS ALTERAÇÕES AMBIENTAIS NA APP DA BACIA HIDROGRÁFICA DO RIBEIRÃO DE BAIXO - MS
}

\author{
Eduardo Vinícius Rocha Pires ${ }^{1}$
}

Andréia da Cruz Rodrigues ${ }^{2}$

\author{
Rafael Martins Brito ${ }^{3}$
}

\begin{abstract}
RESUMO
O objeto de estudo desta pesquisa é a Bacia Hidrográfica do Ribeirão de Baixo, que se localiza dentro do Parque Natural Municipal Salto Sucuriú, reserva legal de compensação ambiental da PCH Costa Rica e sofre influência direta da mesma. O objetivo principal desta pesquisa é indicar problemas e alterações ambientais causados pela ação antrópica desordenada dentro de sua APP, mesmo esse objeto de estudo localizando-se no interior Parque Natural. Com a abordagem sistêmica, foi feita uma pesquisa de campo para analisar as alterações ambientais nesse curso da bacia hidrográfica, analisando sua APP e os processos antrópicos.
\end{abstract}

PALAVRAS-CHAVE: Análise Ambiental; Teoria Geral dos Sistemas; Bacia Hidrográfica.

\section{PRELIMINARY SYSTEMIC ANALYSIS OF CHANGES IN ENVIRONMENTAL APP OF HYDROGRAPHIC BASIN RIBEIRÃO DE BAIXO - MS}

\begin{abstract}
The object of this research is the Basin of Ribeirão de Baixo, which is located within the Municipal Natural Park Salto Sucuriú, legal reserve for environmental compensation PCH Costa Rica and is under direct influence of the same. The main objective of this research is to indicate problems and environmental changes caused by human action cluttered inside your APP, this same study object locating within Natural Park. With a systemic approach, a field survey was made to analyze the environmental changes that course watershed, analyzing their APP and anthropogenic processes.

KEY-WORDS: Environmental Analysis; General Systems Theory; Hydrographic Basin.

\footnotetext{
${ }^{1}$ Graduado em Geografia Licenciatura e Mestrando do Programa de Pós-Graduação em Geografia da UFMS/CPTL; e-mail: drocha.geo@gmail.com.

${ }^{2}$ Graduado em Geografia Bacharelado e Bolsista FUNDECT pelo Programa de Pós-Graduação em Geografia da UFMS/CPTL; e-mail: andreia.delacruzz@gmail.com.

${ }^{3}$ Graduando em Geografia- Bacharelado da UFMS/CPTL, e-mail: patriciaufmsgeografia@gmail.com.
} 


\section{PRELIMINAR ANÁLISIS SISTÉMICAS DE CAMBIOS EN EL APP DE LA CUENCA HIDROGRÁFICA RIBEIRÃO DE BAIXO - MS}

\section{RESUMEN}

El objeto de esta investigación es la Cuenca de Ribeirão de Baixo, que está situado dentro del Parque Natural Municipal Salto Sucuriú, la reserva legal para PCH compensación ambiental Costa Rica y está bajo la influencia directa de la misma. El objetivo principal de esta investigación es indicar los problemas y los cambios ambientales causados por la acción humana desordenada dentro de su aplicación, este mismo objeto de estudio la localización dentro del Parque Natural. Con un enfoque sistémico, se realizó un estudio de campo para analizar los cambios ambientales que supuesto de cuencas, el análisis de su APP y procesos antropogénicos.

PALABRAS CLAVE: Análisis Ambiental; Teoría General de Sistemas; cuencas

\section{INTRODUÇÃO}

Esta é uma pesquisa preliminar, à qual visa uma futura ação de implantação do plano de manejo na área estudada.

Os cenários de ambientes construídos ou transformados pela ação do homem ocupam a maior parte dos sistemas ambientais. O homem transforma os espaços através da derrubadas de matas, da implantação de pastagens e cultivos, da construção de estradas, portos aeroportos, represas, da retificação e canalização de curso d'água, da implantação de indústrias e áreas urbanas. (FLORENZANO, 2002 apud MIRANDOLA-AVELINO, 2006).

Segundo ORTIZ FLÓREZ (2011), a premissa básica de impacto ambiental é que o projeto, ao utilizar os recursos e valores ambientais, não gere uma perda maior de bem-estar que o ganho obtido com ele. Por essa razão, o principal propósito é buscar formas em que se possa desenvolver o projeto com os mínimos danos possíveis ao ambiente, e que, ao mesmo tempo, se promova o desenvolvimento econômico e social.

MENDONÇA (1991) corrobora que, se por um lado, a natureza desenvolve-se e evolui de acordo com suas próprias leis, a sociedade, pela sua própria característica de entidade teleológica, desenvolve-se e evoluem de acordo com objetivos próprios, traçados por indivíduos e/ou grupos que, utilizando a faculdade de pensar, produzem as transformações sociais na busca de satisfazer desejos e necessidades humanas. 
Sabendo disso, tomamos como objeto de estudo a Bacia Hidrográfica do Ribeirão de Baixo, que se localiza dentro do Parque Natural Municipal Salto Sucuriú, reserva legal de compensação ambiental da $\mathrm{PCH}$ Costa Rica e sofre influência direta da mesma.

Nas atuais condições de intensificação da produção social, tem-se dado cada vez mais importância ao papel da avaliação da informação com o objetivo de organizar de forma racional as estruturas produtivas e a tecnologia industrial contemporânea, estando condicionado ao intenso desenvolvimento da informática, como um amplo campo de elaboração automática da informação em todas as esferas da atividade humana (DAVIDCHUK e LINNIK, 1989).

Com o objetivo de estruturar sistemas informativos, direcionados a garantir as informações necessárias para a utilização racional e proteção dos recursos naturais e o meio ambiente, foi desenvolvido os sistemas geoinformativos ou Sistemas de Informação Geográfica(SIG).

O objetivo principal desta pesquisa é indicar problemas e alterações ambientais causados pela ação antrópica desordenada dentro de sua APP, mesmo esse objeto de estudo localizando-se no interior Parque Natural.

Através da caracterização do meio, pode-se compreender a dinâmica do processo e reunir subsídios para o planejamento e gestão eficazes. Sabendo que o uso dos recursos naturais interfere nos seus ciclos, tem-se trabalhado atualmente no contexto das bacias hidrográficas, pois, esta forma de planejamento e gestão do meio físico, permite utilizar os conhecimentos delimitados por uma unidade de planejamento.

Segundo Bertalanffy(1972) apud PIRES(2011), existe uma relação entre todos os elementos e constituintes da sociedade. Os fatores essenciais dos problemas públicos, das questões e programas a adotar devem sempre ser considerados e avaliados como componentes interdependentes de um sistema total.

A partir dos anos de 1960 difundiu-se amplamente o enfoque ou método sistêmico em muitas disciplinas científicas. Antes dessa época, porém, algumas idéias geográficas têm sido por essência sistêmica (CHRISTOFOLETTI, 1979). 
Desta forma, pode-se definir como sistema ao conjunto de elementos que se encontram em relação entre si, e que formam uma determinada unidade e integridade.

Conduzidos por esta concepção, os estudos descartam a abordagem meramente setorial que enfatiza cada componente individualmente, seja a vegetação, a água, os minerais, seja o próprio homem, detendo-se na análise integrada e correlações guiadas pelos princípios de interdisciplinaridade.

Atualmente, estar atento ao desempenho ambiental, à vitalidade econômica deve estar no mesmo nível de prioridade dos resultados de demanda e produção de uma grande empresa. O administrador deve estar atento aos compromissos legais e também buscar a melhoria contínua das práticas ambientais, normas técnicas e guias de conduta, segundo os princípios do "desenvolvimento sustentável". (MIRANDOLA; GARCIA NETTO, pág.189, 2012 )

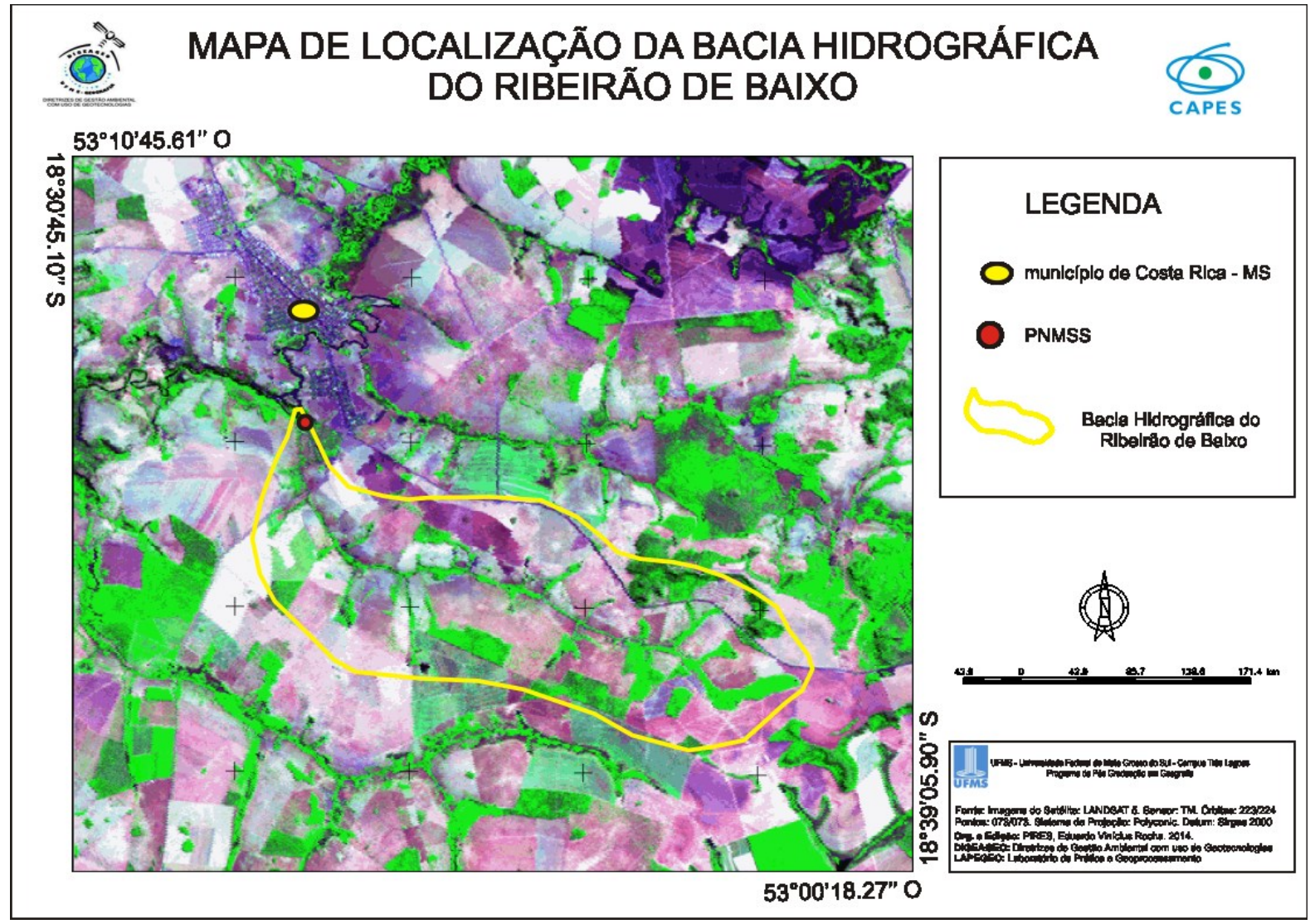

Figura 1: Mapa de Localização da Bacia Hidrográfica. 


\section{DESENVOLVIMENTO}

O presente trabalho apoia-se no enfoque sistêmico, considerando o ambiente como um sistema ambiental, baseado na perspectiva de Bertalanffy (1972), propondo o entendimento deste sistema ambiental, a partir da Teoria Geral dos Sistemas. Bertalanffy constata que, para o ambiente ser entendido, esse não pode ser encarado como uma soma de suas partes, tende ser considerado as partes que compõem o sistema, para que se possa analisar o todo. Este sistema é compreendido, então, como Sistema, Subsistema e Parte componente.

É necessário estudar não somente partes e processos isoladamente, mas também resolver os decisivos problemas encontrados na organização e na ordem que os unifica, resultante da interação dinâmica das partes, tornando o comportamento das partes diferente quando estudado isoladamente $\mathrm{e}$ quando tratado no todo (BERTALANFFY, 1972, p.53).

Ainda sobre a abordagem sistêmica da Bacia Hidrográfica do Ribeirão de Baixo, Guerra e Cunha (1998), fala que a bacia hidrográfica é uma unidade integradora dos setores que compõe a paisagem (naturais e sociais) e deve ser administrada com esta função, a fim de que os impactos ambientais sejam minimizados.

Para fazer as análises, então, em primeiro momento foi feito um trabalho de campo no município de Costa Rica - MS, onde se encontra o Parque Natural Municipal do Alto Sucuriú, onde por sua vez está inserido na Área de Preservação Permante da Bacia Hidrográfica do Ribeirão de Baixo (à jusante).

Foram feitas análises e interpretações que geraram informações de alterações ambientais nos limites da APP do objeto de estudo (Tabela 1), que auxiliará em um mapeamento futuro da área. 
Tabela 1: Alterações Ambientais nas APP's na Bacia do Ribeirão de Baixo -MS, em 2014.

\begin{tabular}{|c|c|c|}
\hline $\begin{array}{c}\text { Pontos } \\
\text { Analisados }\end{array}$ & Alterações Ambientais encontradas & Ponto de Referência \\
\hline 1 & $\begin{array}{c}\text { Margem direita do Ribeirão de Baixo não respeitando APP (área de } \\
\text { recreação- quiosques e piscina); Apenas } 5 \text { metros de mata ciliar; } \\
\text { Entrada para o curso do rio causando assim um processo de } \\
\text { assoreamento. }\end{array}$ & \\
\hline 2 & $\begin{array}{l}\text { Margem direita do Ribeirão de Baixo não respeitando APP (área de } \\
\text { recreação- quiosques, bancos, mesas e piscina); Apenas } 5 \text { metros de } \\
\text { mata ciliar; Intensivo processo de assoreamento. }\end{array}$ & \\
\hline 3 & $\begin{array}{l}\text { Entrada improvisada para o leito do rio feita na margem direita; } \\
\text { Intensivo processo de assoreamento; Mata ciliar não passa dos } 5 \\
\text { metros de largura. }\end{array}$ & \\
\hline 4 & $\begin{array}{l}\text { Margem direita do Ribeirão de Baixo não respeitando APP (área de } \\
\text { recreação- gramado, banco e entrada para o leito do rio). }\end{array}$ & \\
\hline 5 & $\begin{array}{c}\text { Margem esquerda do Ribeirão de Baixo; Possui mata ciliar, porém } \\
\text { não é densa e não passa de } 5 \text { metros, utilizada como pastagem; } \\
\text { Observa-se um processo de assoreamento na margem esquerda, } \\
\text { próximo à borda. }\end{array}$ & \\
\hline 6 & $\begin{array}{l}\text { Margem esquerda do Ribeirão de Baixo; Não possui mata ciliar; APP } \\
\text { utilizada como área de pastagem; Processo de erosão na borda. }\end{array}$ & \\
\hline 7 & $\begin{array}{l}\text { Margem direita do Ribeirão de Baixo; não respeitando APP (área de } \\
\text { recreação- piscina e quiosques); }\end{array}$ & \\
\hline
\end{tabular}

\section{CONCLUSÕES}

De acordo com o Plano de manejo do Parque Natural Municipal do Alto Sucuriú, existem ações previstas para um uso e ocupação ordenado da terra.

Ações como, combater o processo erosivo no talude da área em regeneração onde se encontram antropizadas e com processos erosivos, monitoramento nas áreas de cerrado sentido restrito no período de frutificação, plantio de espécies nativas de ocorrência natural do local em áreas de enriquecimento, plantar espécies nativas 
coletadas no município e de viveiro florestal, com ocorrência na área específica para plantio, recuperar a mata ciliar no córrego Ribeirão de Baixo (próximo á piscina).

Com a pesquisa de campo e análise sistêmica preliminar sob essa área, conclui-se que, mesmo o Parque Natural Municipal do Alto Sucuriú sendo uma área de compensação ambiental da $\mathrm{PCH}$ Costa Rica, não há perspectiva de um Planejamento, Gestão e Manejo do mesmo.

O ecoturismo, quando feito de forma planejada e gerenciado de forma ordenada, auxilia no processo de recuperação ou estabilização do meio.

Verificou-se que é preciso reter a ação antrópica em ambas as margens. Na margem direita, a ação antrópica dentro dos limites da APP e da mata ciliar( uso de churrasqueiras, restos de carvão, bancos, piscinas, quiosques, etc) podem causar modificação direta -e em alguns pontos, indireta- na qualidade da água( Oxigênio dissolvido, Ph, O.R.P, Salinidade e Temperatura da Água, estando todos os processo interligados) e na paisagem. Já na margem esquerda, onde não existe mata ciliar consideravelmente densa e possui APP tomada pela pastagem e vegetação arbustiva, o processo de erosão e assoreamento são visíveis e podem vir à interferir na qualidade da água e no curso do rio.

Ao se estudar o uso e cobertura da terra para fins de planejamento ambiental dentro de uma bacia hidrográfica, é importante que se entenda como o homem, com a sua dinâmica social, se apropriou destes espaços e os transformou por meio de seu trabalho, alterando os fluxos de matéria e energia no ambiente que ele se adequou. Algumas modalidades estarão mais degradadas do que outras, variando de um lugar para o outro, e a partir disso pode-se propor medidas prioritárias à recuperação de áreas degradadas.

Estes problemas podem ser mitigados, caso entre em vigor as ações programadas já no Plano de Manejo do Parque Natural Municipal Salto Sucuriú, na qual uma destas ações está citada como "Recuperar a mata ciliar no córrego Ribeirão de Baixo".

Para que não acarrete em problemas maiores (assoreamento, ravinamento, vossorocamento) na área, um intensivo processo de planejamento e reeducação ambiental deve ser feita com urgência e cautela, pois como citado anteriormente, 
quando se estuda um sistema, se faz necessário entender a dinâmica deste, pois seus reflexos são repassados de forma dinâmica, acarretando problemas ambientais em efeito cascata.

Em relação ao método e procedimentos utilizados, ficou evidente sua eficácia, pois, a aquisição, manipulação e armazenamento dos dados da área de estudo foram processados e transformados em informações que podem subsidiar o planejamento da área.

Além da utilização de práticas de manejo, é essencial o cumprimento da legislação, quanto as áreas de APP, reserva legal e corredores ecológicos das propriedades rurais e até mesmo do PNMSS.

A fragilidade dos ambientes naturais face as intervenções humanas é maior ou menos em função de suas características genéticas. O princípio, salvo algumas regiões do planeta, os ambientes naturais mostram-se ou mostravam-se em estado de equilíbrio dinâmico até o momento em que as sociedades humanas passaram progressivamente a intervirem cada vez mais intensamente na exploração dos recursos naturais.( ROSS, 1993)

Em suma, segundo FERREIRA (2010) apud PIRES (2013) planejar significa elaborar planos de melhoria, que significa encontrar diretrizes para corrigir os espaços mal organizados e improdutivos. Significa, também, encontrar meios e propiciar condições para interferir nos setores menos favoráveis de uma estrutura ou de uma conjuntura.

\section{REFERÊNCIAS}

AB'SÁBER, Aziz, Nacib. Geografia e planejamento. In: 2 geografia e planejamento. Instituto de geografia da Universidade de São Paulo. Edanee: São Paulo, 1969.

BERTALANFFY. V. L. Teoria Geral dos Sistemas. Petrópolis: Vozes, 1975

DAVIDCHUK, V.N. e LINNIK, V.G. O bloco paisagístico do sistema de informação geográfica. Revista da Universidade Estadual de Moscou. N.5, 1989.

FERREIRA, C.C. Uso de imagens de sensoriamento remoto para mapeamento do uso e ocupação da terra da Bacia Hidrográfica do Alto Sucuriú- MS-BR. II Simpósio Internacional da Cartografia na Geografia. São Paulo. 2010.

MENDONÇA, Francisco. Geografia Física: ciência huma? - 2ª Ed. São Paulo: Contexto, 1991. 
MENDONÇA, Francisco. Geografia e Meio Ambiente. São Paulo: Contexto, 1993.

MIRANDOLA-AVELINO, Patricia. Helena. Análise geo - ambiental multitemporal para fins de planejamento ambiental: um exemplo aplicado à bacia hidrográfica do Rio Cabaçal Mato Grosso - Brasil. Tese de Doutorado em Geografia do Programa de Pós Graduação em Geografia da Universidade Federal do Rio de Janeiro, 2006, 317 p.

RODRIGUEZ, José Manuel Mateo(Org.). Geoecologia das Paisagens: uma visão geossistêmica da análise ambiental. $3^{\mathrm{a}}$ ed. - Fortaleza: Edições UFC, 2010.

ROSS, J.L.S. Análise Empírica dos Ambientes Naturais e Antropizados. Laboratório de Geomorfologia - Departamento de Geografia. FFLCH - USP, São Paulo, 1993. Disponível em: <http://www.semarh.ba.gov.br/gercom/analise_empirica.pdf >.Acesso em 20 de agosto de 2014.

ORTIZ FLÓREZ, Ramiro. Pequenas Centrais Hidroelétricas. São Paulo: Oficina de Textos, 2014. 